\title{
Suppression of prolonged fever during treatment of pulmonary tuberculosis: importance of using twice versus single daily dose of prednisolone
}

\author{
K. F. CHUNG \\ M.R.C.P.
}

\author{
P. D. SNASHALL \\ M.R.C.P.
}

Department of Medicine, Charing Cross Hospital Medical School, London W6 8RF

\section{Summary}

We describe the clinical course of a patient with extensive pulmonary tuberculosis, in whom fever persisted despite adequate anti-tuberculous and broad-spectrum antibiotic treatment. $A$ once daily morning dose of prednisolone failed to suppress the fever, but a twice daily regime was successful.

KEY WORDS: pulmonary tuberculosis, fever, prednisolone.

\section{Introduction}

Despite the advent of extremely effective antituberculous drug regimes, fever may still persist for more than 2 weeks in many patients being treated for pulmonary tuberculosis (Kablawi et al., 1981). We present such a patient in whom the fever was effectively suppressed by a twice-daily regime of prednisolone, but not by a single daily dose.

\section{Case report}

A 46-year-old single Irish museum attendant was admitted to hospital with a 3 month history of anorexia, severe weight loss, fever, night sweats and cough. On examination, he was pyrexial $\left(38^{\circ} \mathrm{C}\right)$, cachectic and extremely weak, such that he could hardly stand up. The liver was palpable at $8 \mathrm{~cm}$ below the costal margin. There was no splenomegaly. The chest X-ray (Fig. 1) showed bilateral upper zone shadowing, more extensive at the left apex with cavitation. Sputum smears showed numerous acidfast bacilli on Ziehl-Nielsen staining and, within 2 weeks of culture, Mycobacterium tuberculosis was grown. Other investigations were: haemoglobin 11.8 $\mathrm{g} / \mathrm{dl}$ with normal white cell and differential counts; erythrocyte sedimentation rate (ESR) $100 \mathrm{~mm} / \mathrm{hr}$; plasma sodium $128 \mathrm{mmol} /$ litre; plasma potassium 3.2 mmol/litre; urea $1.7 \mathrm{mmol} /$ litre and creatinine 45 $\mu \mathrm{mol} / \mathrm{litre}$. A low plasma osmolality (259 mOsm/litre) in the presence of a urine osmolality of

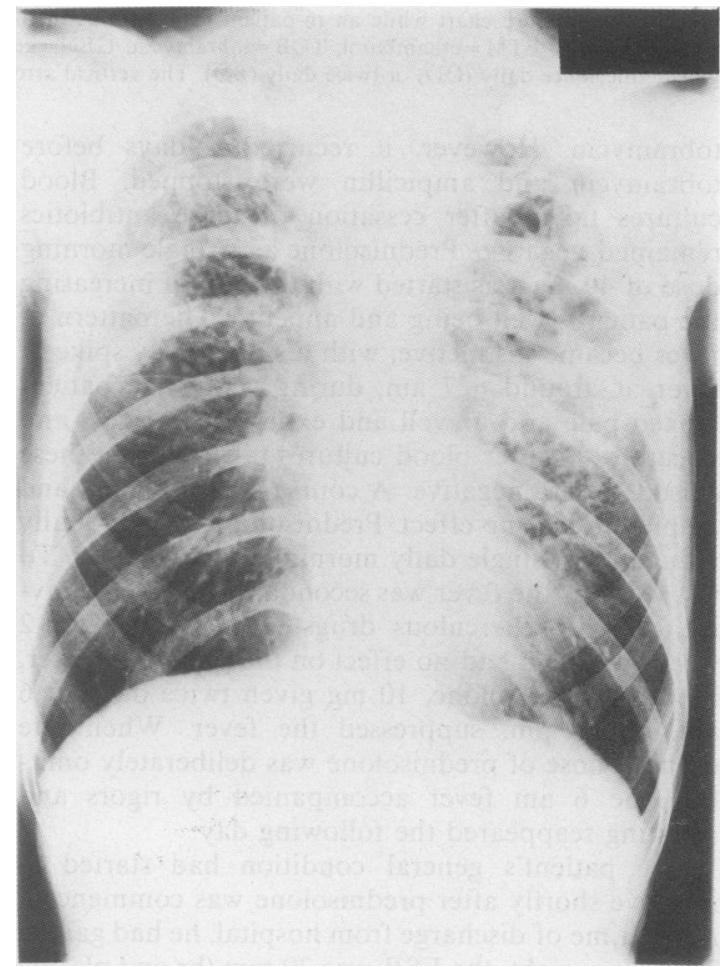

FIG. 1. Chest X-ray on admission showing bilateral upper zone shadowing with cavitation.

$638 \mathrm{mOsm} /$ litre supported the presence of inappropriate antidiuretic hormone secretion.

Rifampicin, ethambutol and isoniazid, to which the mycobacterium was sensitive, were started after a week. Ampicillin was also given, as the sputum also grew Pneumococcus. A high protein and calorie diet with fluid restriction (1 litre/day) was commenced. The course of the fever is shown on Fig. 2. After a short period of abatement, the fever reappeared and was temporarily suppressed during a course of 


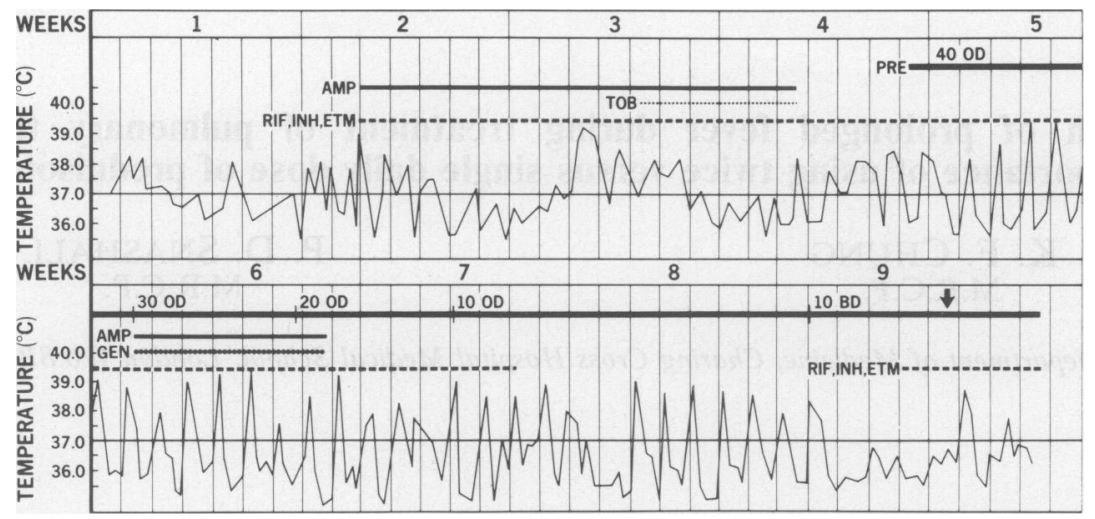

FIG. 2. Temperature chart while an in-patient. The various medications as indicated are as follows: AMP=ampicillin; RIF =rifampicib; $\mathrm{INH}=$ isoniazid; $\mathrm{ETM}=$ ethambutol; TOB = tobramycin; $\mathrm{GEN}=$ gentamicin and PRE = prednisolone. The doses of prednisolone are in mf given either once daily (OD) or twice daily (BD). The vertical arrow indicates the day when the evening dose of prednisolone was omitte

tobramycin. However, it recurred 2 days before tobramycin and ampicillin were stopped. Blood cultures taken after cessation of these antibiotics remained negative. Prednisolone as a single morning dose of $40 \mathrm{mg}$ was started with the aim of increasing the patient's well-being and appetite. The pattern of fever became distinctive, with a single daily spike of fever at around 6-7 am, during which the patient looked pale and unwell and experienced rigors and sweating. Further blood cultures taken during these episodes were negative. A course of gentamicin and ampicillin had no effect. Prednisolone was gradually reduced to a single daily morning dose of $10 \mathrm{mg}$. To test whether the fever was secondary to drug sensitivity, all anti-tuberculous drugs were stopped for 2 weeks, but this had no effect on the pattern of fever. Finally, prednisolone, $10 \mathrm{mg}$ given twice daily at 6 am and $6 \mathrm{pm}$, suppressed the fever. When one evening dose of prednisolone was deliberately omitted, the 6 am fever accompanied by rigors and sweating reappeared the following day.

The patient's general condition had started to improve shortly after prednisolone was commenced. At the time of discharge from hospital, he had gained $2.5 \mathrm{~kg}$ in weight, the ESR was $20 \mathrm{~mm} / \mathrm{hr}$ and plasma sodium and potassium concentrations were within normal range. He continued on prednisolone $10 \mathrm{mg}$ twice daily at home, in combination with rifampicin and isoniazid and denied any recurrence of morning fevers and rigors at home. Prednisolone was discontinued 3 months after discharge from hospital.

\section{Discussion}

In a recent study (Kablawi et al., 1981), 36\% of a group of 59 febrile patients with pulmonary tuberculosis being treated with isoniazid and ethambutol plus either streptomycin or rifampicin had persisten fever for more than 2 weeks. Similar results weres reported in an earlier study (Berger and Rosenbaum $\stackrel{?}{2}$ 1968) where patients were treated with isoniazid and para-aminosalicyclic acid with or without streptomy cin. Patients with clinically and radiologically faradvanced disease, as in this patient, were more lik 140

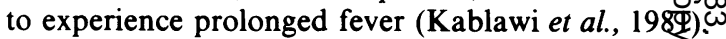

The cause of the prolonged fever in this patien fisp unlikely to be due to a pulmonary or extrapulmonaty bacterial infection as the fever did not respond to intensive antibiotic therapy. Febrile reactions witho spiking fever and rigors have been described in $\mathbb{Q}$ patients treated with isoniazid alone or in combina $\Rightarrow$ tion with other anti-tuberculous drugs (Dasta, Priog and Kurzok, 1979; Berte, DiMase and Christianson, 1964). However, discontinuation of all these drugs did not result in a reduction or disappearance of the fever. It is more likely that the prolonged fever was associated with the pulmonary tuberculosis itself, but the precise mechanism is unclear. Release of endoge 3 . nous pyrogens from monocytes, which are activated by lymphokines released by specifically sensitized lymphocytes in cell-mediated immunity (Atkins,o Francis and Bernheim, 1978) might be involved.

Corticosteroids were used in this patient in order to은 increase well-being and appetite (Horne, 1960) and a once-daily, morning dose of prednisolone was insti- $\Omega$ tuted so as to minimise pituitary-adrenal axis sup- $-{ }^{0}$ pression (Nichols, Nugent and Tyler, 1965). The use ${ }_{\mathrm{W}}^{N}$ of corticosteroids as an antipyretic agent in pulmo-nary tuberculosis has not been previously reported though it has been used in other bacterial infections, in conjunction with antibiotic therapy (Klastersky 1971). With a morning daily dose of prednisolone therapy, the pyrexia regularised and occurred ato around 6 am daily, but was abolished when predniso $-\overrightarrow{\mathbb{D}}$ lone was given twice-daily. The most likely explana- $-\vec{D}$ 
tion for these observations is that prednisolone given orally in normal subjects has a relatively short plasma half-life of 2 to $3.5 \mathrm{hr}$ (Pickup, 1979). Rifampicin may further decrease it through liver enzyme induction (Edwards et al., 1974). Thus, the plasma concentration of prednisolone after a single morning dose would have been virtually nil in the mornings, thus allowing the pyrexia to occur then.

After exclusion of concomitant bacterial infections and of drug sensitivity, prednisolone may be used to suppress the prolonged fever of patients treated for advanced pulmonary tuberculosis, but it should, at least, be given on a 12-hr daily basis.

\section{References}

Atkins, E., Francis, L. \& Bernheim, H.A. (1978) Pathogenesis of fever in delayed hypersensitivity: role of monocytes. Infection and Immunity, 21, 813.

Berger, H.W. \& Rosenbaum, I. (1968) Prolonged fever in patients treated for tuberculosis. American Review of Respiratory Diseases, 97, 140.

BerTe, S.J., DiMase, J.D. \& Christianson, C.S. (1964) Isoniazid, para-amino-salicylic acid and streptomycin intolerance in 1744 patients. American Review of Respiratory Diseases, 90, 598.

DAsta, J.F., Prior, J.A. \& KURzok, S. (1979) Isoniazid-induced fever. Chest, 75, 196.

Edwards, D.M., Courtenay-Evans, R.J., Galley, J.M., HunTER, J. \& TAIT, A.D. (1974) Changes in cortisol metabolism following rifampicin therapy. Lancet, ii, 549.

HORNE, N.W. (1960) Prednisolone in the treatment of pulmonary tuberculosis. A controlled trial. British Medical Journal, 2, 1751.

Kablawi, S.S.O., Jay, S.J., Stonehill, R.B. \& NoRTON, J. (1981) Response of patients on therapy of pulmonary tuberculosis. American Review of Respiratory Diseases, 123, 20.

KLASTERSKY, J. (1971) Etude experimentale et clinique des effets favorables et defavorables de la fievre et de l'administration de corticoides au cours d'infections bacteriennes. Acta Clinica Belgica, 26 (Supp. 6); 1.

NiCHOLS, T., NUgENT, C. \& TYLER, F. (1965) Diurnal variation in suppression of adrenal function by glucocorticoids. Journal of Clinical Endocrinology and Metabolism, 25, 343.

PICKUP, M.E. (1979) Clinical pharmacokinetics of prednisone and prednisolone. Clinical Pharmacokinetics, 4, 111. 